\title{
Second Chance School Students' Attitudes Toward the Use of Computers in Domokos Prison, Greece
}

\author{
Georgios Giannoukos (Corresponding author) \\ Hellenic Open University, Greece \\ E-mail: g.giannoukos@gmail.com \\ Remos Armaos \\ Hellenic Open University, Greece
}

Received: 18-10-2015

doi:10.7575/aiac.ijels.v.4n.1p.9
Accepted: 24-01-2016

URL: http://dx.doi.org/10.7575/aiac.ijels.v.4n.1p.9
Published: 31-01-2016

\begin{abstract}
This paper is an attempt to explore educational issues in a school operating in a prison in the hope that findings will be useful in further and larger-scale research. The objective of the study was to investigate the attitudes of inmates attending the Second Chance School, Domokos prison, Greece, towards the use of computers with the help of the research scale, Computer Anxiety Rating Scale (CARS) by Heinssen, Glass \& Knight (1987). The research took place in February 2014. Thirty eight inmate students, from different countries, aged 21 to 45 who were enrolled in the 1 st and 2nd year of the Second Chance School were the subjects of the study. The research showed that respondents were very enthusiastic about learning about computers but most were anxious that large amounts of data could accidentally be erased. The learners believed that computers are essential in education and the workplace and also believed that they were able to acquire relevant skills. The final result of the research revealed increased anxiety about computers probably because inmate students have limited access to them. This could be an obstacle in the learning process as a reluctance to use computers could hinder computer assisted learning.
\end{abstract}

Keywords: adult education, prison education, second chance school, computers, technology

\section{Introduction}

Second Chance Schools (SCSs) are schools that provide secondary level education and operate in the morning in prisons. The certificate awarded after a successful two-year period of study is equivalent to the qualification at a conventional secondary school. In total 7 SCSs operate in prisons in Greece, of which 6 operate in men's prisons and 1 in a women's prisons.

Important studies (e.g., Nuttall, Hollmen \& Staley, 2003) demonstrate the effectiveness of education in prison aimed at reducing delinquency. According to Linton (2004), approximately $60 \%$ of former prisoners in the USA end up back in prison, while other research suggests that the rate of recidivism for inmates educated in the USA ranges from $15 \%-30 \%$ (Slater, 1995). Chappell (2002) concludes that the higher the educational level of the inmates the greater the reduction of recidivism.

As reported by Muñoz (2009), prison should be an environment for prisoners so as to allow for positive change, and enable prisoners to acquire knowledge, skills and abilities that will help them to reintegrate into society. The main target of the education of prisoners is, in addition to reacquainting them with education, to take advantage of unexploited free time in order to minimize the suffering caused by incarceration.

The goal of the study was to investigate the attitudes of inmates attending the Second Chance School, Domokos prison, Greece, towards the use of computers with the help of the research scale, Computer Anxiety Rating Scale (CARS) by Heinssen, Glass \& Knight (1987).

The use of technology in the educational process is an important factor in successful teaching because it allows students to learn more in less time. Technology allows students to monitor their own learning process and also gives them access at the touch of a button to a large amount of information (Lam \& Lawrence, 2002). According to Goddand (2002), research shows that there has been an increase in the number of computers used at home and there is also a growing number of technological media in schools for educational purposes. Ginsburg (1998) proposes four approaches related to the integration of technology in adult education. These are:

- technology as a learning subject

- technology as a medium of instruction

- technology as an adjunct to teaching

- technology as a teaching tool 
There have been several studies investigating the benefits of computers in adult learning (Askov \& Clark, 1991, Bixler \& Askov, 1994, Rachal, 1995, Turner, 1998). According to Askov and Bixler (1996) the use of information technology can help adult learners to develop various skills such as problem solving and the development of logical thinking. There are many ways in which technology can be used in adult education such as its use in teaching or as a supplement to education (Ginsburg, 1998).

A survey by Barbeite and Weiss (2004) on 226 people, using the Computer Anxiety Rating Scale (CARS) by Heinssen, Glass and Knight (1987), showed little anxiety about computers. Murthy's (2004) research on 67 people revealed similar results. A comparative survey (Tekinarslan, 2008) of 52 Dutch and 54 Turkish students also showed low stress levels as far as computers were concerned.

\section{Method}

A quantitative research method was used and a closed-ended questionnaire. The research was conducted on adult male learners of SCS Domokos prison at both school levels. The 38 male students who participated in the research project were from 22-44 years old and were from different countries of origin in Europe, Africa and Asia. To research the attitudes of learners of SCS Domokos prison towards the use of computers we chose the Computer Anxiety Rating Scale (CARS) of Heinssen, Glass \& Knight (1987). CARS was developed by Heinssen, Glass and Knight in 1987 and contains 19 statements based on a five-point Likert scale (strongly disagree $=1$ - disagree $=2$ - Neither agree nor disagree $=3-$ agree $=4-$ strongly agree $=5$ ). The questionnaire consists of 9 positively worded and 10 negative statements. The score ranges from 19-95 units. According to Heinseen et al (1987) a score above 55 points indicates increased anxiety about computers and below 32 little anxiety. Heinssen et al. (1987) reported the internal-consistency reliability coefficient for their scale to be .87 , with a test-retest reliability of $.70(n=270)$.

The questionnaire (see Appendix) was translated from English to Greek by the researchers and was checked by a native speaker of English with a high level of knowledge of Greek. The foreign students who participated in the research project had a good knowledge of Greek.

\subsection{Research procedure}

The final distribution of the questionnaire was preceded by a pilot questionnaire involving 6 students of SCS Domokos prison, 3 of the students were enrolled in the first year and the other 3 in the second year. The selection of these learners was made randomly and the pilot questionnaire was distributed by the researcher. Then, after errors which were relative to the layout of the questionnaire were corrected, the questionnaire was distributed to learners by the researcher from February 3, 2014 to February 6, 2014. Of the 40 questionnaires handed out 38 were completed. It should be noted here that we didn't modify the original questions of the questionnaire.

\subsection{Issues of ethics}

The research complied with ethical requirements and the students took part in this research at their own will, none of them was forced to participate, and all of them had been previously informed by the researcher about the study and its objectives. The questions were such so as not to offend the participants and not lead to a decrease in self-esteem. Also there was no attempt to change their attitudes towards technology and computers. The study was conducted in such a manner so as not to create stress and / or fatigue to the participants. All students who took part in the study received the same treatment and the same respect from the researcher and participation was anonymous.

\section{Results}

The demographics of the questionnaire showed that of the 38 people who completed the questionnaire, 11 are aged 21 24, 15 are aged 26-30, 7 are 31-35, 4 are 36-40 years old, while 1 person is 44 years old. Of these students, 17 were enrolled in the 1 st year and the remaining 21 in the 2 nd year of secondary school.

The first sentence of the questionnaire refers to whether respondents feel insecure about their ability to interpret a computer printout. The responses of the learners show that 3 people strongly disagreed, 15 disagreed, 3 neither agreed nor disagreed but 15 agreed and 2 strongly agreed. We note here that almost half of the respondents agree and half disagree. For the next statement "I look forward to using a computer in my job", 4 people strongly disagreed, 4 disagreed, 19 agreed and 11 strongly agreed. For the following statement "I do not think I would be able to learn a computer programming language", 9 students strongly disagreed, 20 disagreed, 6 neither agreed nor disagreed, 2 agreed and 1 strongly agreed. The graph below shows the results of the proposal stating that "The challenge of learning about computers is exciting" We observe that the vast majority were very enthusiastic about learning computers. 


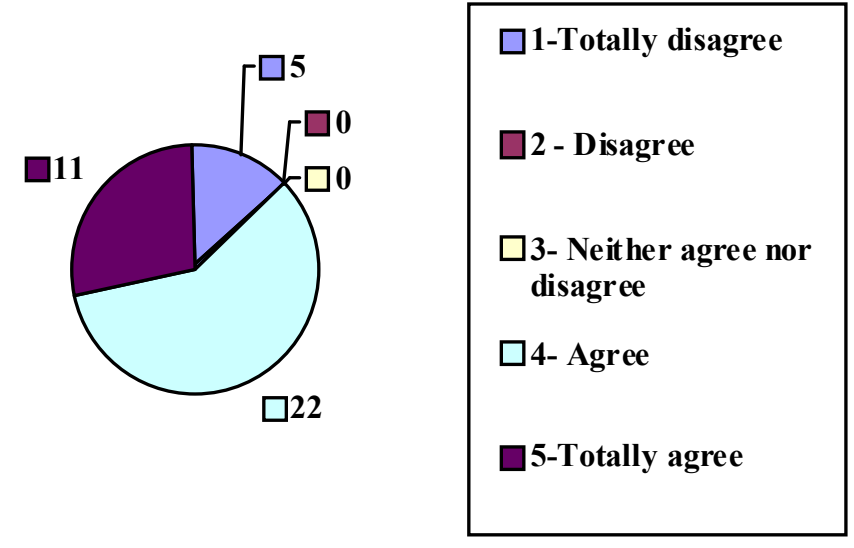

Figure 1. The challenge of learning about computers is exciting

The statement that followed was whether respondents are confident that they can acquire skills related to computers. Here 12 strongly agreed, 24 agreed and 2 neither agreed nor disagreed, which means 36 out of 38 people are confident that they are able to acquire relevant skills. In the next statement, which says that anyone can learn to use a computer if patient and motivated, 17 people strongly agreed and 21 simply agreed. It is interesting that none disagreed with the above statement. Subsequently the statement asking if they are afraid that if they start to use computers will become addicted to them and they will lose some of their cognitive skills, 15 strongly disagreed, 10 disagreed, 3 neither agreed nor disagreed while 9 agreed and 1 strongly agreed. Therefore, 25 of the 38 respondents did not agree with the above statement. For the following the statement "I am sure that with time and practice I will be as comfortable working with computers as I am in working with typewriters", 3 strongly disagreed, 5 disagreed, 8 neither disagreed nor agreed, 16 agreed and 6 strongly agreed. In statement number 10 "I feel that I will be able to keep up with the advances happening in the computer field", 4 people disagreed, 15 neither disagreed nor agreed, 11 agreed and 8 strongly agreed. For the next statement "I dislike working with machines that are smarter than I am" 19 students strongly disagreed, 10 disagreed, 3 neither disagreed nor agreed, 4 agreed and 2 strongly agreed. The results of the statement "I feel apprehensive about using computers" are noteworthy. These results are shown in the chart below. The vast majority of learners said they disagreed.

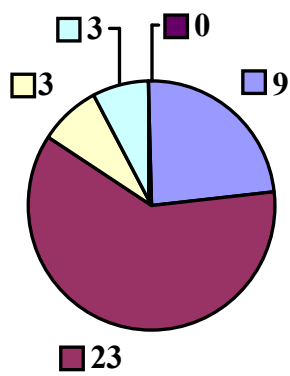

\section{$\square$ 1-Totally disagree \\ $\square 2$ - Disagree \\ $\square 3$ - Neither agree nor disagree \\ 口4- Agree \\ 5-Totally agree}

Figure 2. I feel apprehensive about using computers

For statement number 13 "I have difficulty in understanding the technical aspects of computers", 8 people strongly disagreed, 8 disagreed, 12 neither disagreed nor agreed, 7 agreed and 3 strongly agreed. In the statement," It scares me to think that I could cause the computers to destroy a large amount of data by hitting the wrong key" 3 people strongly agreed, 19 agreed, 12 disagreed and 4 strongly disagreed. So, most had this fear of computers. The results of the following statement "I hesitate to use a computer for fear of making mistakes that I cannot correct" showed that 3 students strongly disagreed, 14 disagreed, 5 neither disagreed nor agrees, 12 agreed and 4 strongly agreed. For statement number 16 "You have to be a genius to understand all the special keys contained on most computer terminals" 11 people strongly disagreed, 18 disagreed, 5 agreed and 4 strongly agreed. The answers for the statement "If given the opportunity, I would like to learn about and use computers" showed that 6 students disagreed, 5 neither 
disagreed nor agreed, 19 agreed and 8 strongly agreed. The results of the statement that learners avoid computers because they are unfamiliar and create fear were enlightening. Here, 11 strongly disagreed while 27 disagreed. The results of the statement that computers are indispensable tools in both education and work are shown in Figure below. We note that 20 of the 38 respondents believe that computers are essential in education and work.

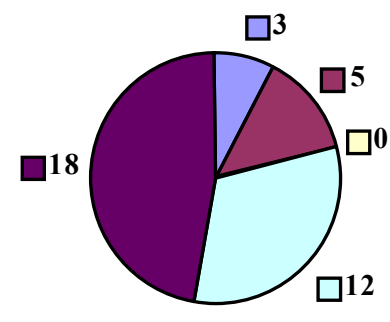

\section{$\square$ 1-Totally disagree \\ 2 - Disagree \\ $\square$ 3- Neither agree nor disagree \\ $\square$ 4-Agree \\ 5-Totally agree}

Figure 3. I feel computers are necessary tools in both educational and work settings

The following table shows the Sample Standard Deviation, the Variance (Sample Standard), the Population Standard Deviation, the Variance (Population Standard) as well as the Mean score garnered by the questionnaires from our research.

Table 1. CARS questionnaire Rating and Averages

\begin{tabular}{ll}
\hline Sample Standard Deviation, s & 6.2598996987952 \\
Variance (Sample Standard), s ${ }^{2}$ & 39.186344238976 \\
Population Standard Deviation, $\sigma$ & 6.1769834590793 \\
Variance (Population Standard), $\sigma^{2}$ & 38.15512465374 \\
Total Numbers, N & 38 \\
Sum: & 2278 \\
\hline Mean (Average): & 59.947368421053 \\
\hline
\end{tabular}

The following figure shows a graph of each questionnaire and its rating score

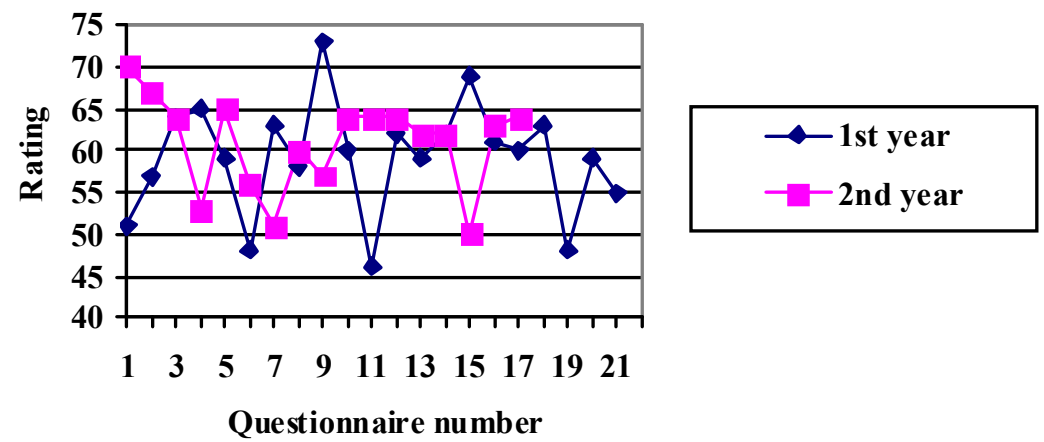

Figure 4. CARS questionnaire Rating

The following figure shows the average score of the students' answers in the first year, in the second year and an average rating of these two. 


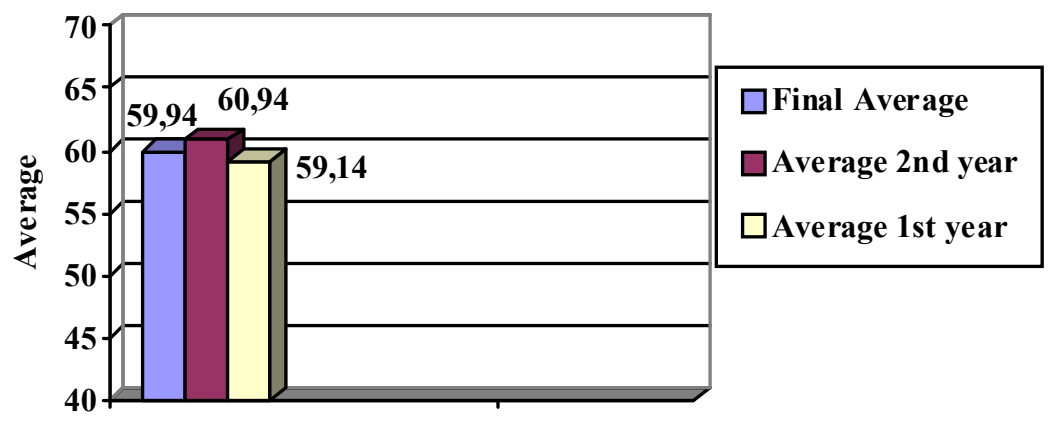

Figure 5. Column chart of the values

\section{Discussion and Conclusions}

The results of the questionnaire show ratings ranging from 46 to 73 points with an average of 59.94. According to Heinssen et al (1987) this average score, because it is more than 55 units, means respondents exhibit increased stress about the use of computers. We observe that the score of 59.94 does not differ so much from the score of 55 suggested by Heinssen et al (1987) so as to indicate a great deal of anxiety. According to a survey carried out by Barbeite and Weiss (2004) on 226 people using the same questionnaire, there was an average score of 30.52 points which means little anxiety about computers. Murthy's (2004) research on 67 people showed similar results where the average was 49.9 points. Also a comparative survey (Tekinarslan, 2008) among 52 Dutch and 54 Turkish students showed low stress about computers with averages of 33.28 and 37.57 points respectively.

In conclusion, we observe that the results of our research do not agree with the above research at all. Possible increased anxiety about computers is due to the fact that our sample is students who are imprisoned and have limited access to computer use namely, only during the operation of the school for a few hours per day and they may not have mastered the use of computers and technology generally because of the strict framework of the operation of the prison.

\section{References}

Askov, E.N., \& Bixler, B. (1996). You just received a windfall for technology! So how do you select the CAI software? Adult Learning, 8, 23-28.

Askov, E.N., \& Clark, C.J. (1991). Using computers in adult literacy instruction. Journal of Reading, 34(6), $434-437$.

Barbeite, G. F., \& Weiss, E. M. (2004). Computer self-efficacy and anxiety scales for an Internet sample: Testing measurement equivalence of existing measures and development of new scales. Computers in Human Behavior, 20(1), $1-15$.

Bixler, B., \& Askov, E.N. (1994). Characteristics of effective instructional technology. University Park, PA: Institute for the Study of Adult Literacy.

Chappell, C.A. (2002). Post-secondary correctional education and recidivism: A meta-analysis of research conducted 1990-1999. The Journal of Correctional Education, 55(2), 148-169.

Goddard, M. (2002). What do we do with these computers? Reflections on technology in the classroom. Journal of Research on Technology in Education, 35 (1), 19-26.

Ginsburg, L. (1998). Integrating Technology into Adult Learning. In C. Hopey (Ed.), Technology, basic skills and adult education: Getting ready and moving forward (pp.37-45): Information Series no. 372. Columbus, OH: ERIC Clearinghouse on Adult, Career, and Vocational Education, Center on Education and Training for Employment, College of Education, the Ohio State University.

Heinssen,R.K., Class,C.R., Knight,L.A. (1987). Assessing computer anxiety:

Development and validation of computer anxiety scale. Computer in Human

Behavior, 3, 49-59.

Lam, Y., \& Lawrence, G. (2002). Teacher-student role redefinition during a computer-based second language project: Are computers catalysts for empowering change? Computer Assisted Language Learning, 15 (3), $295-315$. Linton, J. (2004). U.S. department of education update. The Journal of Correctional Education, 55(4), 274-276. Muñoz, V (2009). The Right to education of persons in detention, Report of the special rapporteur on the right to education, Human Rights Council, UN. 
Murthy, U. S. (2004). Individual differences and the use of collaborative technologies in education: An empirical investigation. In Proceedings of the 37th Hawaii international conference on system sciences.

Nuttall, J., Hollmen, L. \& Staley, E. (2003). The effect of earning a GED on recidivism rates. The Journal of Correctional Education, 54(3), 90-94.

Rachal, J. (1995). Adult reading achievement comparing computer-assisted and traditional approaches: A comprehensive review of the experimental literature. Reading Research and Instruction, 34(3), 239-258.

Tekinarslan, E. (2008). Computer anxiety: A cross-cultural comparative study of Dutch and Turkish university students. Computers in Human Behavior, 24, 1572-1584.

Turner, T.C. (1998). An overview of computers in adult literacy programs. Lifelong Learning, 11(8), 9-12.

\section{APPENDIX}

Computer Anxiety Rating Scale - CARS (Heinssen, Glass \& Knight, 1987)

Instructions:

For each statement, decide whether you disagree or agree with the statement using the following 5 point scale ranging from strongly disagree to strongly agree. In the box to the right of each statement, fill in the number on the 5 point scale that best describes your level of disagreement or agreement.
1: Strongly disagree
2. Disagree
3. Undecided
4. Agree
5. Strongly agree

1. I feel insecure about my ability to interpret a computer printout.

2.* I look forward to using a computer in my job.

3. I do not think I would be able to learn a computer programming language.

4.* The challenge of learning about computers is exciting.

5.* I am confident that I can learn computer skills.

6.* Anyone can learn to use a computer if they are patient and motivated.

7.* Learning to operate computers is like learning any new skill - the more you practice, the better you become.

8. I am afraid that if I begin to use computers I will become dependent upon them and lose some of my reasoning skills.

9.* I am sure that with time and practice I will be as comfortable working with computers as I am in working with a typewriter.

10. $\quad$ I feel that I will be able to keep up with the advances happening in the computer field.

11. I dislike working with machines that are smarter than I am.

12. I feel apprehensive about using computers.

13. I have difficulty in understanding the technical aspects of computers.

14. It scares me to think that I could cause the computer to destroy a large amount of data by hitting the wrong key.

15. I hesitate to use a computer for fear of making mistakes that I cannot correct.

16. You have to be a genius to understand all the special keys contained on most computer terminals.

17.* If given the opportunity, I would like to learn about and use computers.

18. I have avoided computers because they are unfamiliar and somewhat intimidating to me.

19.* I feel computers are necessary tools in both educational and work settings.

Note: * indicates items that are reverse-scored. Higher scores indicate higher levels of computer anxiety. 